\title{
REPRESENTACIONES DE HORREA EN LA MUSIVARIA ROMANA. PROBLEMAS PARA SU IDENTIFICACIÓN
}

\author{
HORREA REPRESENTATIONS IN ROMAN MOSAICS. PROBLEMS OF IDENTIFICATION
}

\author{
JAVIER SALIDO DOMÍNGUEZ1 \\ Escuela Española de Historia y \\ Arqueología en Roma-CSIC \\ LUZ NEIRA JIMÉNEZ² \\ Universidad Carlos III de Madrid
}

\section{INTRODUCCIÓN}

Las representaciones de almacenes y graneros (horrea) no son muy frecuentes en la musivaria romana, pero nos aportan información muy interesante sobre aspectos que desconocemos por el calamitoso estado de conservación en que se encuentran la mayoría de los restos arqueológicos correspondientes a estos edificios.

El carácter secundario de estas construcciones en el trazado urbanístico explica que los escasos testimonios iconográficos que se conservan sobre dichas edificaciones queden relegados a su inclusión en vistas parciales de paisajes rurales o de instalaciones portuarias y comerciales, poco comunes también en la musivaria romana (Cf. Noguera, 1995-1996; Neira, 1997). Son las evocaciones de paisajes portuarios, imágenes idílicas de pesca o de acciones comerciales, presentes tanto en la musivaria, escultura o pintura como en otras artes menores (gemas, recipientes de vidrio, metálicos, lucernas, etc.), las que nos ofrecen la posibilidad más clara de contemplar estos edificios en alzado.

La dificultad para identificar los horrea en los mosaicos, similares en aspecto a otro tipo de construcciones, ha derivado en la ausencia de estudios focalizados en analizar la información que estas figuraciones nos aportan para comprender el funcionamiento, alzado, divisiones, instalaciones asociadas o detalles de los almacenes, una imagen que desconocemos a nivel arqueológico debido al pésimo estado en el que han llegado hasta nosotros los restos conservados. Esto

1. Este trabajo es resultado de la investigación llevada a cabo en la Universidad Carlos III de Madrid con un Contrato Postdoctoral de la A4U y en la EEHAR-CSIC en la modalidad JAE-Doc del Programa «Junta para la Ampliación de Estudios» cofinanciada por el Fondo Social Europeo.

2. Este trabajo se inscribe entre los resultados de investigación llevadas a cabo en el marco del Proyecto de Investigación «Producción y comercio de los mosaicos romanos de la Bética». HAR 2010-18594, financiado por el MEC. justifica que los grandes especialistas en el estudio de los horrea hayan minimizado la importancia del análisis de aspectos que resultan verdaderamente importantes para interpretar estas estructuras. Así pues, los excelentes trabajos publicados por Rickman (1971; 1980), Manning (1975) o Gentry (1976) apenas han prestado atención a estas representaciones que pretendemos analizar a continuación.

\section{LOS HORREA EN LA MUSIVARIA ROMA- NA: PROBLEMAS DE INTERPRETACIÓN E IDENTIFICACIÓN}

Las construcciones representadas en la musivaria romana susceptibles de ser interpretadas como horrea romanos son numerosas, pues muchos edificios que forman parte del paisaje de una escena rural, de una ciudad, de una instalación portuaria o de un embarcadero de una gran ciudad o villa marítima pudieron reproducir construcciones que cumplían la función de almacenes. Sin embargo, existen varios problemas para la identificación de las construcciones que nos impiden determinar la funcionalidad exacta de ciertos edificios representados en los mosaicos.

El principal problema que encontramos a la hora de identificar los horrea en las figuraciones musivas es su semejanza iconográfica con otras construcciones urbanas (como macella), cobertizos o viviendas modestas en las imágenes de villae, o con mercados, astilleros, embarcaderos o dársenas en las escenas portuarias. Un ejemplo muy sintomático de esta confusión la encontramos en representaciones como las escenas del puerto de Puteoli bien conocidas por los diseños de las botellas localizadas en Odemira (Portugal), Italia, Norte de África y Augusta Emerita. La ampulla encontrada en ésta última, por ejemplo, diferencia un macellum del resto de construcciones por la inclusión de un enorme arco de medio punto (Bejarano Osorio, 2002, 519); en caso de no aparecer el rótulo MACELLUM podría haber sido identificado erróneamente como un 
horreum, cuestión también aplicable al estudio iconográfico de las representaciones en los mosaicos.

También dificulta la identificación de los horrea el papel secundario en el que se insertan dentro de las imágenes que evocan transacciones comerciales o paisajes idílicos. La propia función de los almacenes que sin duda debió ser considerada marginal por un artista, a pesar de la importancia que jugaban en la vida económica del Imperio romano, llevó a que fuesen menos valorados en las escenas representadas. De ahí que muchas de las imágenes de horrea conservadas formen parte de paisajes convencionales o habituales, repetidos en el fondo de las escenas, formados por la simple superposición de varios edificios. Aunque no podemos dudar de que los artesanos romanos se debieron inspirar en la realidad, en una o varias escenas concretas, es cierto que algunas de estas representaciones debieron resultar de poco interés para un artista al cumplir éstas un papel circunstancial en el paisa$\mathrm{je}^{3}$. Hasta el momento tampoco se han testimoniado mosaicos en los que los horrea aparezcan asociados a actividades que podríamos considerar propiamente annonarias, tales como las mediciones con modii o la redistribución del grano, imágenes que se representaron en pavimentos de edificios o estancias muy concretos como el mosaico blanquinegro del aula dei mensores de Ostia (I,XIX,1.3), donde se muestran medidores de grano (mensores frumentarii) y portadores de sacos (sacarii) (Minaud, 2004).

Un problema añadido es el propio proceso de elaboración de los mosaicos, para cuya realización el artesano emplearía cartones ampliamente difundidos que nos resultan difíciles de asociar a paisajes, construcciones o restos arquitectónicos concretos. Si es difícil identificar escenas con realidades concretas como es el caso de los puertos, cuya imagen ideal debió ser repetida en el mundo antiguo (Noguera, 1995-1996; Neira, 1997), más difícil resulta reconocer edificios que forman parte de dicho paisaje, como los horrea. Aunque es cierto que el arte romano pretende alcanzar un mayor grado de realidad que el helenístico, no cabe duda sobre la dificultad para esta identificación tan precisa.

También complica su identificación la dificultad que existe para diferenciar a nivel arquitectónico los horrea respecto a otros edificios del mundo romano. Los tipos de almacenes y graneros responden a varios modelos, cuyas técnicas constructivas dependen de la función que cumplían. Por otro lado, la información que nos aportan los agrónomos romanos se refiere exclusivamente a los graneros de los establecimientos

3. Podríamos citar numerosos ejemplos que son muy indicativos de esta problemática, aunque al menos podemos destacar representaciones de ciudades menos conocidas como el paisaje sacro-idílico del mosaico conservado en la Galería Ariadne de NuevaYork o de la escena fluvial conservada en el museo de Hama o de un mosaico sirio con escena de una ciudad romana (cf. Lavagne, 2005, 559-566). rurales (Salido, 2011, 44, nota 40). Estos edificios, bien conocidos a nivel arqueológico (Salido, 2010), fueron construidos con pavimentos sobreelevados, con el fin de mantener en el interior de la cámara de almacenaje unas condiciones óptimas de humedad y temperatura para la conservación del grano en su interior (Salido, 2011, 44-46). Estas construcciones pueden ser confundidas visualmente a menudo con simples almacenes que a nivel terminológico también podemos definir como horrea (Salido, 2003-2004, 465-466). Se complica más su reconocimiento en las imágenes portuarias que presentan edificios con grandes arcadas compuestos por enormes cellae abiertas al mar, que bien pudieron servir de horrea, de astilleros o dársenas. En este sentido, los restos arqueológicos conservados pueden corroborar la presencia de dichos almacenes en los puertos conocidos o bien identificados, como el de Roma.

Los modelos son más variados cuando nos referimos a almacenes urbanos y militares. Los estudios realizados por Rickman (1971) permitieron diferenciar dos tipos de horrea: los almacenes donde se guardaban todo tipo de productos (productos agrícolas y/o objetos depositados por particulares) y los graneros que contaban con pavimentos sobreelevados. Diferentes tipos de horrea, incluidos algunos con funcionalidad mixta, han podido ser identificados para el ámbito militar (Salido, 2011). Para el ámbito civil (por el momento el único representado en la musivaria romana respecto a esta cuestión), la mayor parte de los almacenes y graneros respondían a un mismo esquema constructivo; se trata de edificios de planta rectangular que contaban con un patio interno en torno al cual se disponían diversas salas de almacenaje (denominadas en las fuentes clásicas, cellae) y que, a su vez, podían estar divididas en espacios o lugares de menores dimensiones (armarium, arca, arcula, locus, loculus) 4 . Estos horrea, organizados en torno a un patio central, pueden ser fácilmente confundidos con otros edificios comerciales, como los mercados e incluso con valetudinaria $\mathrm{u}$ hospitales 5 .

3. MODELOS ICONOGRÁFICOS DE LOS HORREA ROMANOS EN LAS REPRESENTACIONES MUSIVAS Y SU CONSTATACIÓN ARQUEOLÓGICA

\subsection{Horrea ORganizados EN TORNO A UN PATIO CENTRAL}

La presencia de un edificio distribuido en diversas cellae o estancias organizadas en torno a un patio central puede responder al tipo de almacén de grandes dimensiones presente en numerosos asentamientos de

4. Dig. 1, 15, 3, 2; 32, 52, 9; CIL VI, 33747; CIL VI, 33860.

5. Sobre esta última cuestión, véase Backer, 2002. 


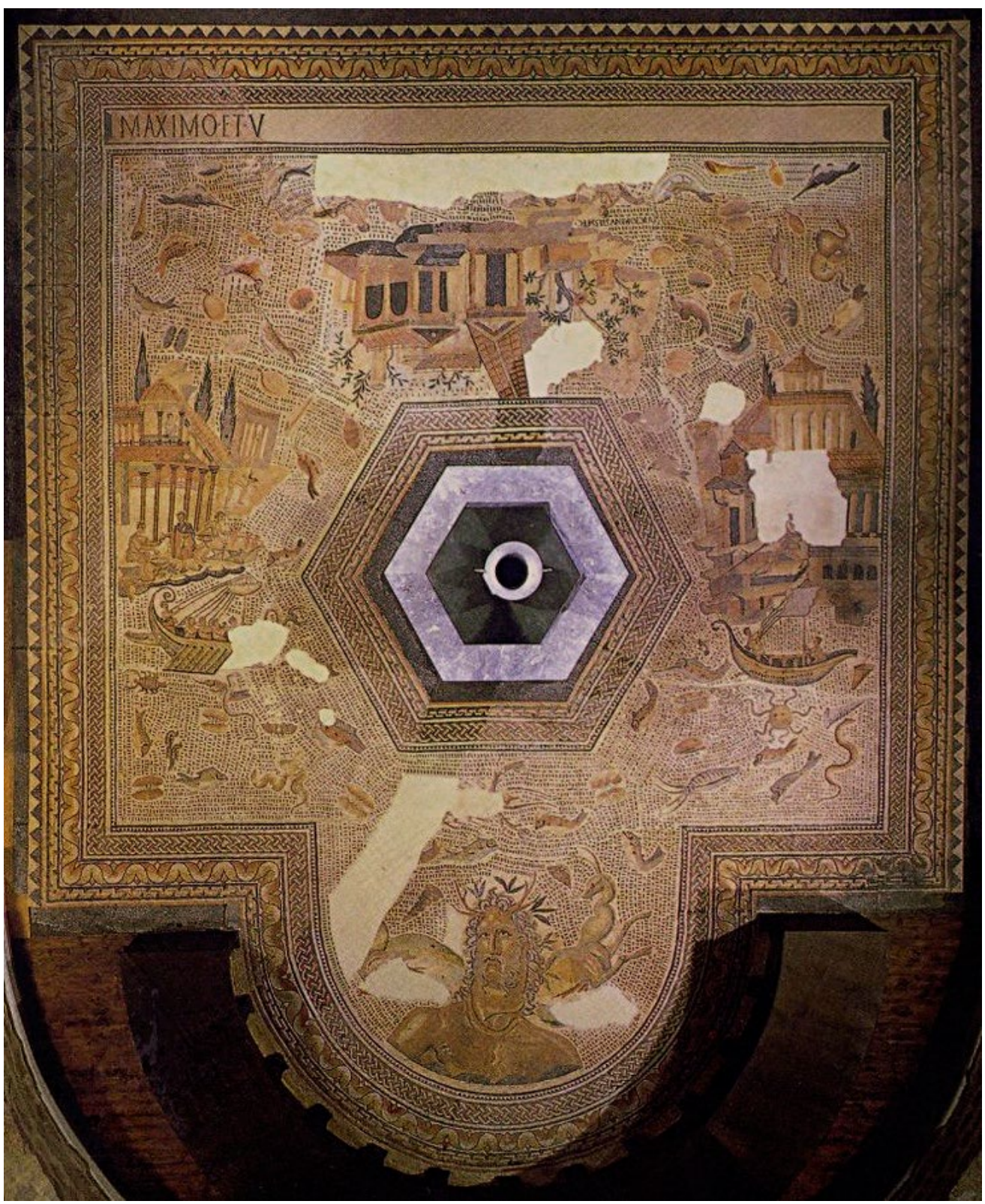

Figura 1: Detalle del mosaico de la villa romana de Bad Kreuznach. Imagen (con modificaciones): http://media-cache-ec0.pinimg.com

carácter civil y militar. Sin duda, es este el modelo más característico y, de hecho, algunas representaciones musivas posiblemente nos muestran su aspecto exterior, aunque la perspectiva simplemente nos muestra su fachada principal.

Una buena prueba de este tipo de horrea con patio es uno de los edificios figurados en el mosaico de Oceanus de la villa romana de Germania, descubierta en Bad Kreuznach en Alemania (Fig. 1). Tal y como ya señaló Rabold (2005, 228-229), una de las escenas de comercio incorporada al mosaico puede corresponder a un horreum con patio central. Se trata de un gran edificio situado en un segundo plano que presenta galerías porticadas, sustentadas por columnas y cubiertas por techumbre a doble vertiente, que rodean un espacio a cielo abierto. Como ya señaló uno de los firmantes de este artículo, el edificio representado se asemeja en su organización y aspecto monumental al presente en los paneles de pasta vítrea hallados en Kenchreai, situado en el lado este del istmo de Corinto (Grecia) (Neira, 1997, 239, fig. 16). En el lado más próximo al espectador, muy afectado por una laguna, presenta galerías adinteladas y en el opuesto, situado en segundo plano, elevadas y estrechas arquerías, tras las que destaca la parte alta de una torre con tejado a cuatro aguas. A pesar del deterioro también se aprecia en el ángulo izquierdo el acceso al edificio, representado de manera diferente al resto del patio (de modo que incluso parece un edificio anexo), con cubierta a dos aguas y un vano adintelado de entrada, que aparece protegido por una especie de voladizo en forma de toldo. Este acceso monumental debió ser muy similar 


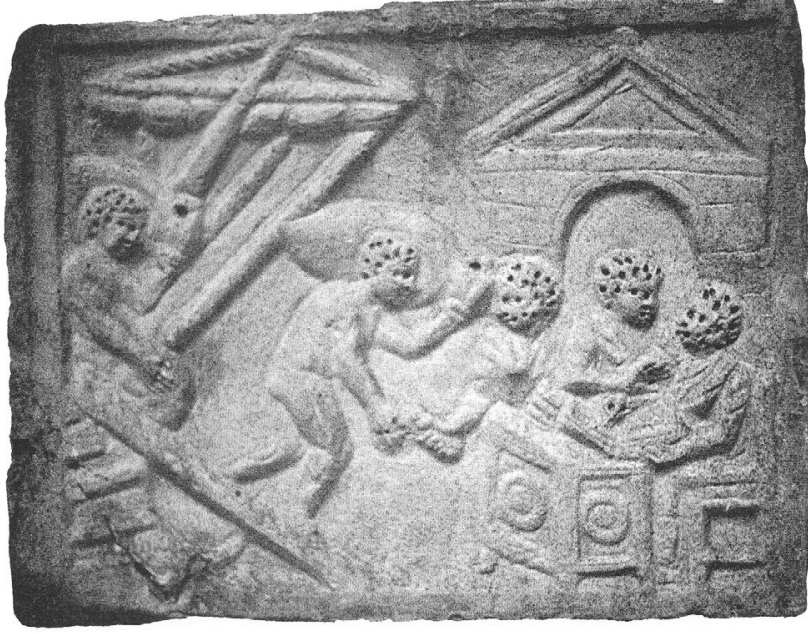

Figura 2: Bajorrelieve localizado en el Portus. Fuente: Virlouvet, 1995, lámina XIII.

al de los Horrea Epagathiana et Epaphroditiana (Reg. I, Is. VIII, 3) de Ostia o al almacén representado en un bajorrelieve del siglo III d.C. localizado en el Portus que muestra una escena de descarga de ánforas desde un barco con un fondo protagonizado por la fachada monumental con frontón triangular de uno de los accesos a un complejo horreario del puerto de la capital del Imperio (Visconti, 1884, no 428; Virlouvet, 1995, 86-87) (Fig. 2). En el extremo inferior derecho, al nivel de las rocas más próximas al agua, un muro con cuatro ventanas arqueadas podrían corresponder a un criptopórtico (Rabold, 2005, 228) 6 .

Una cuestión que permanece abierta en la representación es el edificio que aparece al fondo en forma de torre. En opinión de Rabold (2005 229), podría corresponder a un sacellum o espacio de culto asociado al horreum. A partir de la escasa información que nos ofrece la figuración, nos parece aventurado interpretar dicha construcción como tal, si tenemos presente que los sacella documentados hasta el momento se encuentran en el interior de los patios abiertos. Es el caso del sacellum de los Horrea Agrippiana donde se colocó una estatua del genio horreorum dedicada por tres curatores de un collegium en honor a otros comerciantes relacionados con los almacenes (AE 1915, 97; AE 1923, 57; AE 1927, 97). También en los Horrea di Hortensius de Ostia, se localizó un espacio sacro de aproximadamente $11 \mathrm{~m}^{2}$ pavimentado con un mosaico de opus sectile, fechado por Becatti en la primera mitad del siglo III d. C. (Becatti, 1961, 230-232).

Fuera del ámbito itálico, son muy escasos los restos correspondientes a sacella asociados a almacenes (Salido 2012, 321). Recientemente se han dado a conocer nuevas evidencias de estos espacios sacros en los horrea del puerto fluvial de la ciudad de Hispalis (Sevilla). Las excavaciones arqueológicas desarrolladas

6. Sobre estos edificios, véase Luschin, 2002. en la sevillana avenida de Roma han puesto al descubierto unos edificios identificados como horrea, a los que se asocia un posible sacellum pavimentado con opus signinum que incluye una inscripción donde se mencionan los nombres de los donantes (HEp 13, 630) (Ordóñez y González, 2009, 80). El hallazgo más interesante es la aparición en este edificio de otra inscripción dedicada a [Mercu]rio Aug(usto), que confirma el carácter sagrado de este espacio solemne consagrado a esta divinidad relacionada con el comercio y el culto imperial, como evidencia el epíteto mencionado. Al norte de estos horrea, en la calle Francos, se excavaron más estructuras correspondientes a almacenes que, según la información publicada, están organizados en torno a un patio central, modelo típico de este tipo de edificaciones. Muy próximo a estos grandes horrea, se localizó una inscripción monumental dedicada a $\mathrm{Ve}$ nus Genetrix Augusta por parte de Valeria Valentina en honor de su padre Valerius Valens, atestiguado en los tituli picti del monte Testaccio en Roma (AE 2002, 716; HEp 10, 577). Las últimas investigaciones han relacionado este espacio con los horrea próximos y se ha interpretado como sede de una corporación profesional posiblemente dedicada al comercio del aceite (Ordóñez y González, 2009, 81).

Así pues, los testimonios arqueológicos de sacella en horrea no nos permite por el momento identificar la torre representada con uno de estos espacios sacros. Es posible que dicha construcción haya que ponerla en relación con el carácter defensivo de dichas edificaciones y quizás con una de las tareas encargadas al responsable de las actividades en el almacén, los horrearii, confiados a la custodia de los bienes conservados (Alzon, 1964). Esta función es la que debió motivar los continuos engaños y abusos de horrearii, que en connivencia con los ladrones, facilitaban los robos de los almacenes con fuerza en las puertas. Sabemos que esta práctica debió ser muy extendida, al menos en el siglo III d.C., porque el propio Caracalla incluyó en la legislación la posibilidad de tortura contra los esclavos custodios en caso de robo de los almacenes mediante rotura de las cerraduras (Salido, 2013, 143).

El modelo de horrea representado en la villa romana de Bad Kreuznach, con salas que rodean un patio interno, nos permite identificarlo como un almacén destinado a conservar y guardar productos de diferente naturaleza. La disposición de las salas de almacenaje permite de un modo práctico tener controlada la mercancía con un fácil acceso desde cualquier punto del patio interno. Se podía incluso hacer pasar los productos al interior mediante el uso de carros, aunque la estrechez de las puertas de algunos horrea de Ostia y Portus invitan a pensar en el transporte en sacos o serones al interior del almacén trasladados por trabajadores y portadores (sacarii). Son edificios que debemos concebirlos como espacios de almacenaje temporal, a corto y medio plazo, y de redistribución con fines varios, muy práctico para una economía de subsistencia 

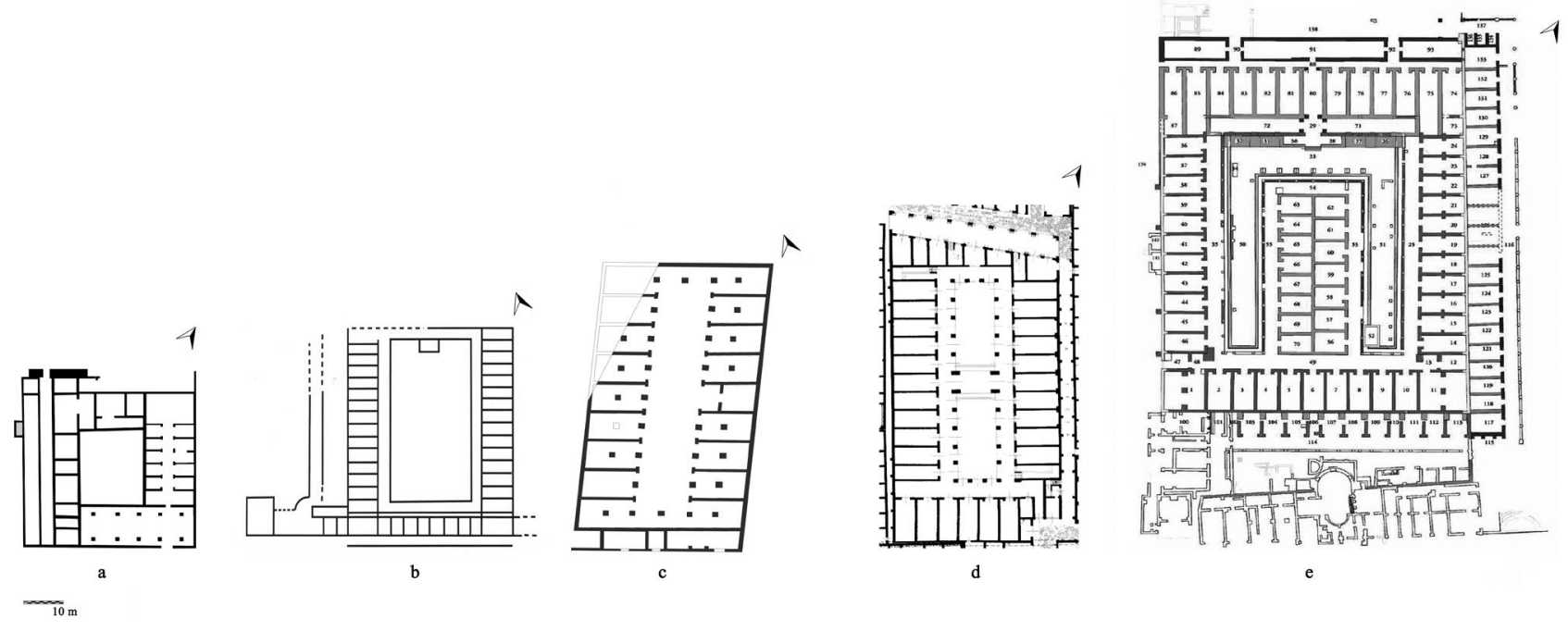

Figura 3: Tipo de almacén organizado en torno a patio central (quadrangle type): a-Bracara Augusta; b- aglomeración secundaria de Barzan; c- grandes almacenes de Colonia Iulia Vienna; d- Piccolo Mercato de Ostia; d- Grandi Horrea de Ostia. Fuente: Salido y Morais, 2014, fig. 1.

y venta continuada que consumía los productos perecederos inmediatamente después de ser enviados desde las zonas de producción (Salido, 2013, 135).

El tipo de horrea representado corresponde por tanto al modelo de almacén organizado en torno a un patio central (quadrangle type), según Rickman $(1971,77)$ (Fig. 3). Presenta una disposición similar a los horrea descubiertos en Ostia, tales como los Horrea di Hortensius (Reg. V, Is. XII, I), Grandi Horrea (Reg. II, Is. IX, 7), Horrea dell'Artemide (Reg. V, Is. XI, 8), Piccolo Mercato (Reg. I, Is. VIII, I), los horrea de la Reg. I, Is. VIII, 2 y los Horrea Epagathiana et Epaphroditiana (Reg. I, Is. VIII, 3). También en Roma se han puesto al descubierto edificios de estas características como los Horrea Agrippina (Astolfi et alii, 1978). Recientemente en Roma el equipo dirigido por Renato Sebastiani ha localizado un enorme horreum del siglo II d.C. próximo al Monte Testaccio (Sebastiani y Serlorenzi, 2011). El edificio, de planta trapezoidal, cuenta con 32 cellae de unos 4,5 de anchura y $9 \mathrm{~m}$ de profundidad en las tres alas. Al igual que los anteriores, debió estar destinado al almacenaje de productos de diversa índole y naturaleza, no solamente grano o cereal.

En el Portus de Roma, también se han localizado grandes horrea organizados en torno a patio. Los enormes almacenes que se construyeron a ambos lados de la dársena en época de Trajano y de Septimio Severo responden a esta clase (Keay et alii, 2005, 82-83, 9598, fig. 5.14 y 5.21). Próximo al Puerto de Roma y al río Tíber se localizó un complejo destinado al almacenaje conocido como Villa d'Erba que mide aproximadamente 54 x $33 \mathrm{~m}$ (Keay et alii, 2005b, 154, fig. $5.58,5.62$ y 5.63$)$. Está dividido a su vez en dos horrea estructurados en torno a patios; el sudoccidental que mide aproximadamente $18 \times 12 \mathrm{~m}$ está rodeado por cellae en tres lados y el flanco noroccidental cuenta con dobles salas. El horreum nororiental mide en torno a $17 \times 15 \mathrm{~m}$.
Recientemente también se han dado a conocer la planta de los diferentes horrea localizados en el portus Iulius, al suroeste de Italia, situado en la ensenada natural del Golfo de Lucrino (Italia), conocido en la antigüedad como lacus Lucrinus o lacus Baianus. En este antiguo puerto se han identificado cuatro horrea dotados de numerosas cellae organizadas en torno a un patio central (Gianfrotta, 2012, 282-284, fig. 4), que se asemejan en planta también al horreum representado en el mosaico de Bad Kreuznach.

En la Península Ibérica, el horreum de la ciudad de Bracara Augusta constituye el primer almacén de dicha tipología reconocido en Hispania (Salido y Morais, 2014). A la espera de más datos sobre el horreum documentado en Hispalis (Sevilla), los restos materiales aparecidos hasta el momento no parecen corresponder a los grandes horrea destinados al almacenaje de productos perecederos. Solamente el edificio de la calle Francos presenta una planta similar a los almacenes urbanos $\mathrm{y}$, según las últimas investigaciones, podría ser el espacio de almacenaje del aceite bético exportado a Roma (Ordóñez y González, 2011, 173). No obstante, a tenor de los datos arqueológicos aparecidos, no parece que podamos confirmar que dicha construcción responda a este modelo de horrea.

En las provincias septentrionales del Imperio, se han localizado restos pertenecientes a horrea organizados en torno a patio central. Además de los de ámbito militar, ya analizados por uno de nosotros de manera específica (Salido, 2011), tenemos constancia de almacenes que responden a esta tipología en asentamientos civiles desde época altoimperial en otras provincias del Occidente del Imperio.

En Britannia, además de los almacenes militares descubiertos en los campamentos legionarios de Inchtuhtil, Caerleon, Chester, o en los fuertes auxiliares de Housesteads, Benwell, Hod Hill, Wallsend, Fendoch y Pen Llystin (Salido, 2011, 120-129), solamente se conoce el almacén de Corstopitum, asentamiento 

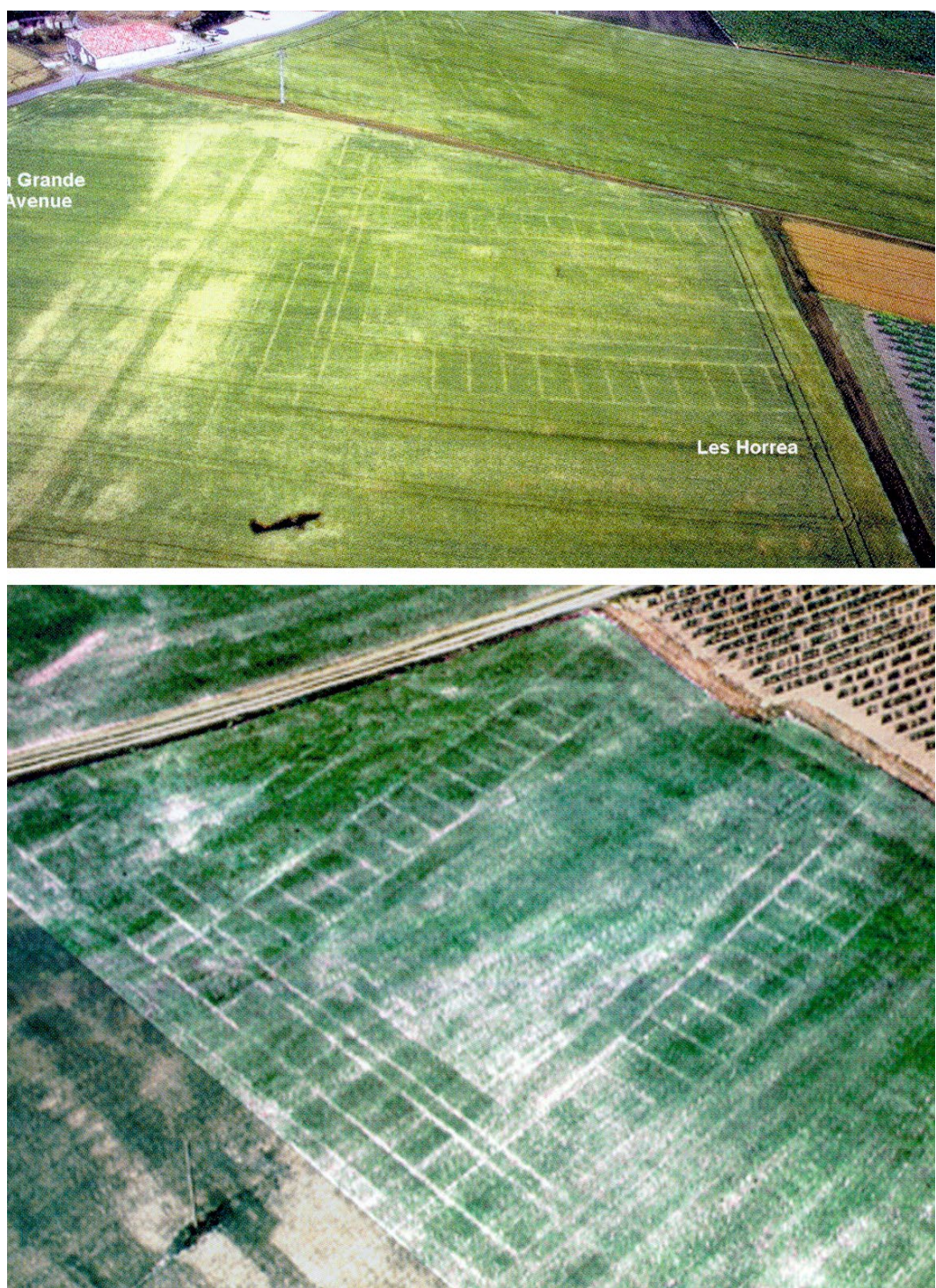

Figura 4: Vista aérea de los horrea de la aglomeración secundaria de Barzan. Fuente: Aupert y Dassié, 1997-1998, figs. 10 y 11.

del que se duda de su carácter militar o civil. Debió construirse en el año 180 d.C., aunque se mantuvo en uso durante los siglos III y IV d.C., momento al que pertenece un tesoro de 400 monedas encontrado en una de las salas del edificio. Birley (1959) interpretó esta construcción como unos principia inacabados. En la actualidad, se piensa que podría tratarse de un mercado (Doré, 2008, 8-11), sin embargo, la planta del edificio estructurado en cuatro flancos divididos en numerosas cellae nos permite mantener la interpretación del edificio como almacén (Rickman, 1971, 260 261; Salido, 2011, 119-121, figs. 7 y 8).

En las provincias de Gallia y Germania, además de los almacenes militares (Salido, 2011, 120-129), se construyeron horrea genéricos destinados a la conservación de alimentos de diferente naturaleza y productos manufacturados en diferentes ciudades. Es el caso del almacén de 60 × $10 \mathrm{~m}$ localizado en la antigua ciudad de Autricum, posiblemente de época altoimperial y organizado en torno a un patio central de tierra batida, que contaba con 18 cellae de 4,15 x 4,25 o 5,90 m cada una (Frézouls, 1997; Bedon, 2001, 137-140; Zahariade, 2007, 1238).

A la fase altoimperial también corresponden los grandes almacenes de uno de los barrios de Colonia Iulia Vienna. La planta del edificio, rectangular (3000 $\mathrm{m}^{2}$ ), construido en la segunda mitad del siglo I d.C., contaba con una sola entrada en la zona meridional que permitía el acceso a un pasillo en torno al cual se hallaban distintas nueve cellae a ambos lados del corredor (La Glay y Tourrenc, 1970, 85, fig. 32).

Un ejemplo muy evidente de horrea organizados en torno a patio se encuentra en la aglomeración secundaria galorromana de Barzan, posiblemente el antiguo Novioregum (Poitou-Charentes, Francia) (Aupert y Dassié, 1997-1998; Aupert et alii, 1998) (Fig. 4). Además de un gran santuario y un fanum de época romana, se han puesto al descubierto dos grandes construcciones que cumplieron la función de horrea. Estos edificios de $60 \times 40 \mathrm{~m}$, orientados en sentido 
noreste-suroeste, cuentan con tres alineaciones de catorce o quince cellae organizadas en torno a un patio.

A estos almacenes que podemos considerar sin duda como horrea organizados en torno a patio, podemos añadir numerosas construcciones de diferentes ciudades del ámbito septentrional del Imperio pero que, a tenor de los restos conservados, no podemos considerar por el momento de este tipo ${ }^{7}$. Es el caso del horreum portuario de la ciudad romana de Burdigala, donde se puso al descubierto un almacén de $50 \mathrm{~m}$ de longitud que contaba con varias cellae (Barraud y Maurin, 1996). Algunos almacenes disponían de diferentes salas de almacenaje, pero no conocemos la planta completa, como los descubiertos en la antigua ciudad, también galorromana, de Avaricum, que presentan una longitud de $45 \mathrm{~m}$ (Ruffier y Dupont, 1993).

En el norte de África, se han localizado graneros con pavimentos sobreelevados (Papi y Martorella, 2007; 2009), pero hasta el momento no se han puesto al descubierto almacenes organizados en torno a patio, a excepción de los grandes horrea localizados en la Proconsular, concretamente los Horrea Caelia - de cuyo nombre latino deriva su posterior denominación como Hergla -, también citados en la Tabula Peutingeriana como Ad Horrea. Las últimas investigaciones realizadas por Françoise Villedieu ${ }^{8}$ nos informan sobre la construcción de unos enormes horrea de planta rectangular con un patio interno que cuenta con numerosas salas destinadas al almacenaje.

A nivel general estos almacenes organizados en torno a un patio central, como el representado en el mosaico de la villa romana de Bad Kreuznach, fueron ampliamente difundidos en época altoimperial tanto en ámbito urbano como portuario y en aglomeraciones secundarias, pero no gozaron de tanto éxito en la fase bajoimperial. Durante este periodo el tipo constructivo corresponde a grandes naves alargadas dotadas de contrafuertes que cuentan en su interior con numerosos pilares y columnas que no sólo soportan el peso de la techumbre, sino que además sirven como delimitadores de los distintos espacios de almacenaje. Éste es el caso de los enormes horrea que se construyen en ciudades como Aquileya (Bertacchi, 1982), Treveris (Eiden y Mylius, 1949), Mediolanum

\footnotetext{
7. Son numerosas las referencias bibliográficas que aluden a la existencia de horrea urbanos pero que, a nivel arqueológico, no nos permiten determinar ni su tipología ni su funcionalidad concreta. Dada la limitación de la extensión permitida para esta publicación, desistimos de la mención de cada uno de estos supuestos almacenes descubiertos en las ciudades.

8. La información de las primeras intervenciones se ha dado a conocer en diversos foros de discusión científica como la Scuola Tematica Internazionale sui magazzini romani, celebradas en septiembre de 2011 en Ostia o la Mesa Redonda Greniers et entrepôts en Afrique du Nord et en Egypte dans l'Antiquité. Typologie, techniques de construction, fonction, contexte de production, celebrada en enero de 2013 en Roma.
}

(Mirabella Roberti, 1984) o Argentoratum (Gissinger, 2002), muy influenciados por el tipo constructivo militar.

\subsection{Horrea PORTUARIOS CON GRANDES ARCADAS ORIENTADAS AL MAR}

En la musivaria romana, también se representan horrea que responden al modelo de almacenes portuarios dotados de enormes arcadas y cellae orientadas hacia la costa que facilitarían notablemente las tareas de carga/descarga de los mercantes. Se trata de un tipo difícil de definir a nivel arqueológico y no resulta fácil asociar estas representaciones con edificios representados en determinadas escenas marítimas.

Algunas construcciones que responden a este modelo han sido identificadas como horrea o almacenes en algunas pinturas de época romana (Ling, 1991, 142149), como en la domus de las ninfas de Neapolis en la Proconsular (Barbet, 1999, 312, láminas CXLV, CXLVI). Son numerosas las representaciones de escenas portuarias que pudieron incluir este tipo de almacenes, pero los detalles no nos permiten identificar con precisión su funcionalidad concreta. La ubicación de dichos edificios efectivamente podría informarnos sobre la existencia de almacenes, aunque no podemos descartar otras funciones como embarcaderos, astilleros o dársenas, es decir, la parte resguardada artificialmente para la cómoda carga y descarga de embarcaciones, de modo que la parte representada no sería la vista desde el mar abierto. Es el caso de las escenas donde se muestran instalaciones portuarias romanas como la del mosaico de Cartago (Dunbabin, 1978, lámina L, 126 y 127), el del «Triunfo de Venus» de Cuicul en Numidia (Dunbabin, 1978, lámina L, 128), el mosaico de la villa romana de la Vega Baja de Toledo (Blázquez, 1982, núm. 25; Balil, 1984, 343-349; Neira, 1997, 242-249) donde aparece un edificio con grandes arcadas que posiblemente corresponde a las dársenas del puerto (Fig. 5 y 6), o el mosaico menos conocido, fechado en el siglo I d.C. procedente de Praenestre y que se conserva en la actualidad en la sacristía de la iglesia de Santa María en Trastevere en Roma (Gasparri, 1983-1984), en el que se muestra el muelle del puerto con numerosas instalaciones portuarias entre las que, además de torre cuadrangular con ventana que se identifica con facilidad, se debían encontrar los horrea para almacenar los productos de los mercantes (Fig. 7). De igual modo, el pavimento de la Casa de Isguntus en Hippo Regius (Numidia), con una representación interpretada como «vista de la propia ciudad de Hipona» (Marec, 1958, 101-108; López Monteagudo, 1994, 12423), muestra dos construcciones de estas características (Dunbabin, 1978, lámina XLIX, 123) (Fig. 8).

Recientemente, sobre el célebre mosaico de la Casa de Isguntus y, en concreto, sobre los dos edificios representados a la derecha del puente, la identificación del situado en segundo plano como un 


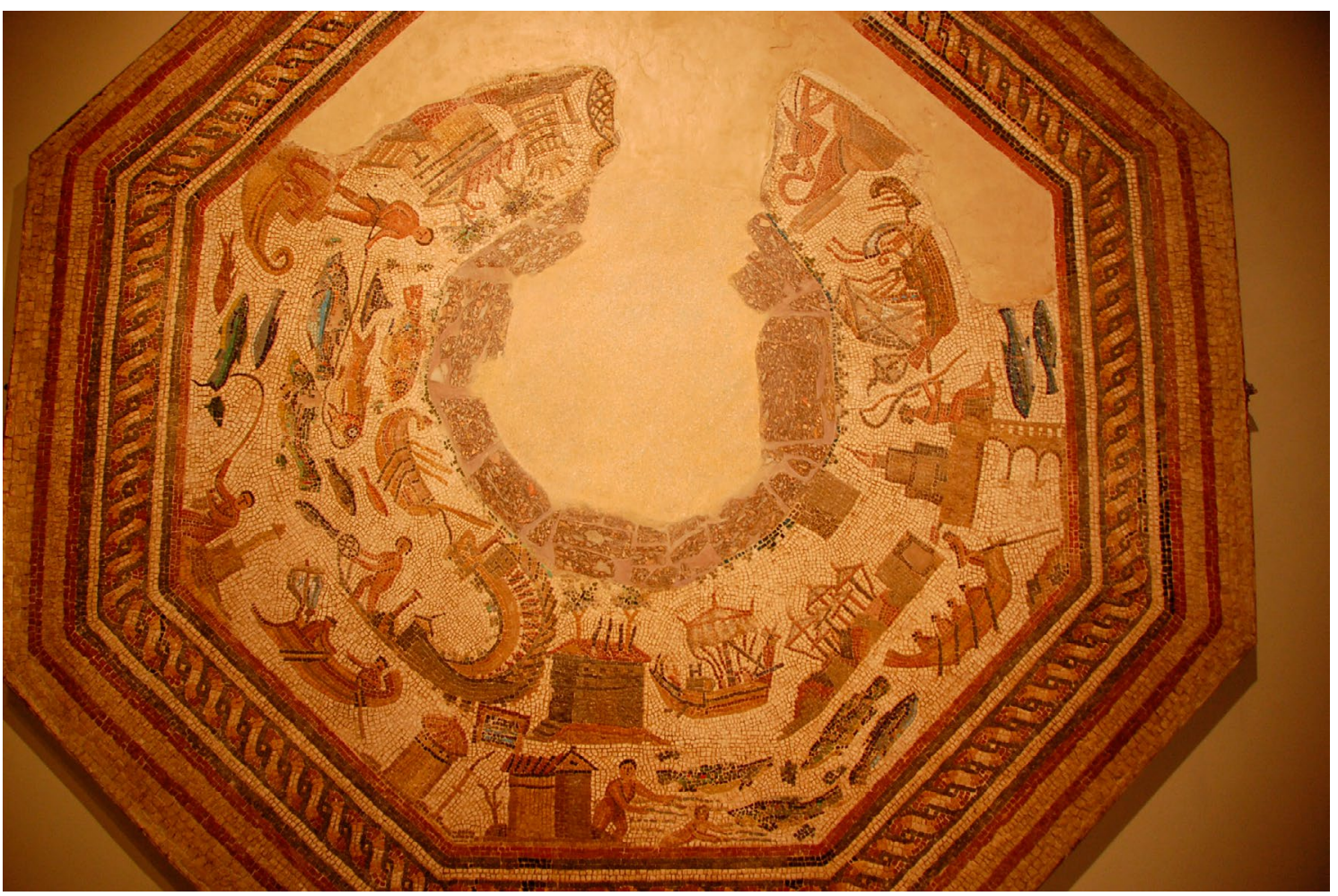

Figura 5: Mosaico de la villa romana de la Vega Baja de Toledo. Imagen: Luz Neira.

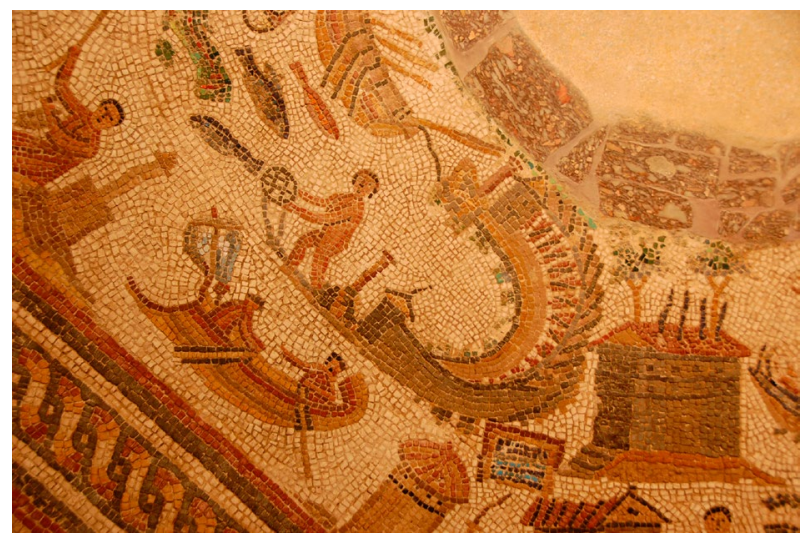

Figura 6: Detalle del mosaico de la villa romana de la Vega Baja de Toledo. Imagen: Luz Neira.

macellum (Dunbabin, 1978, 128) ha sido cuestionada argumentando que los mercados, generalmente en torno a un edículo central, tenían una sola planta (Boulinguez y Napoli, 2008, 718-719). Como nueva hipótesis, estos autores resaltan dos características que lo relacionan con la arquitectura de los graneros: los contrafuertes exteriores y un dispositivo de aireación. Los contrafuertes permitían sostener el peso de las mercancías almacenadas y, sobre todo, contener la presión ejercida sobre los muros laterales, en particular cuando el espesor de éstos era insuficiente, mientras que la existencia de un buen sistema de ventilación era requisito imprescindible en los graneros para asegurar la conservación del cereal y otros productos perecederos.

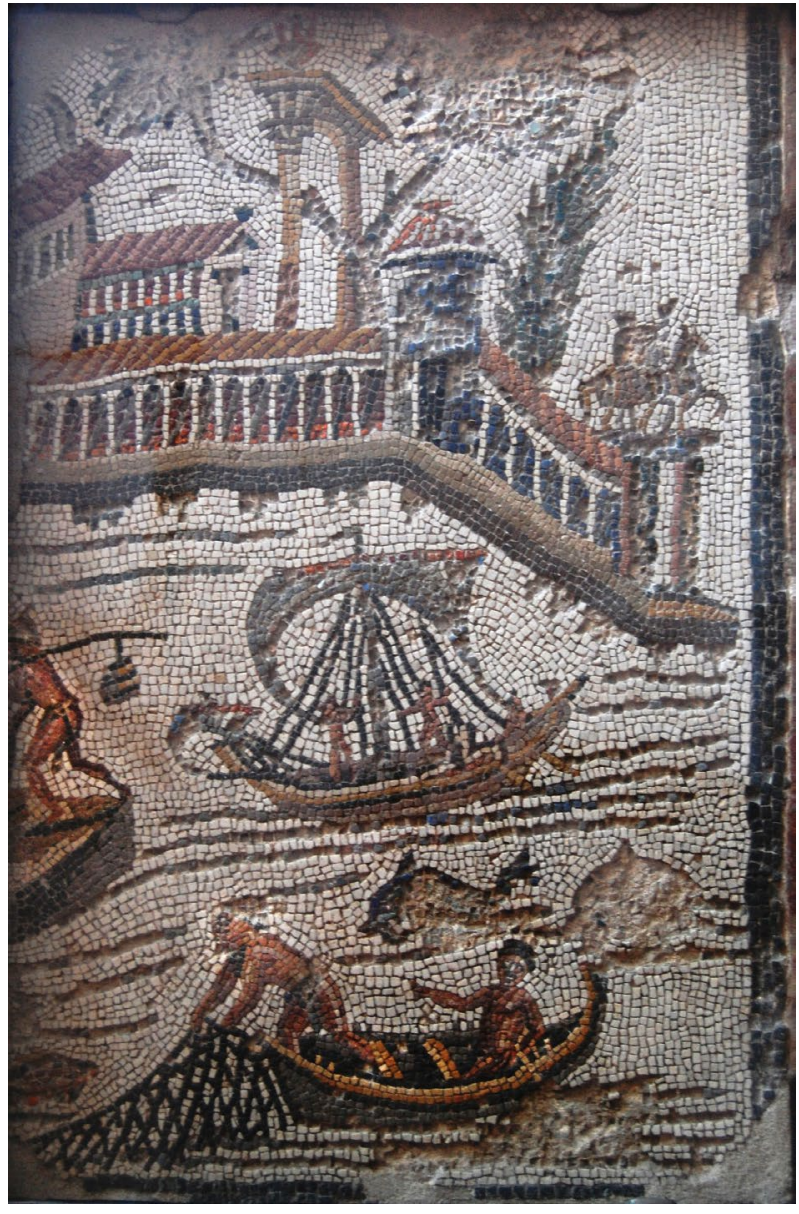

Figura 7: Mosaico procedente de Praenestre conservado en la iglesia de Santa María en Trastevere. Imagen: Javier Salido. 


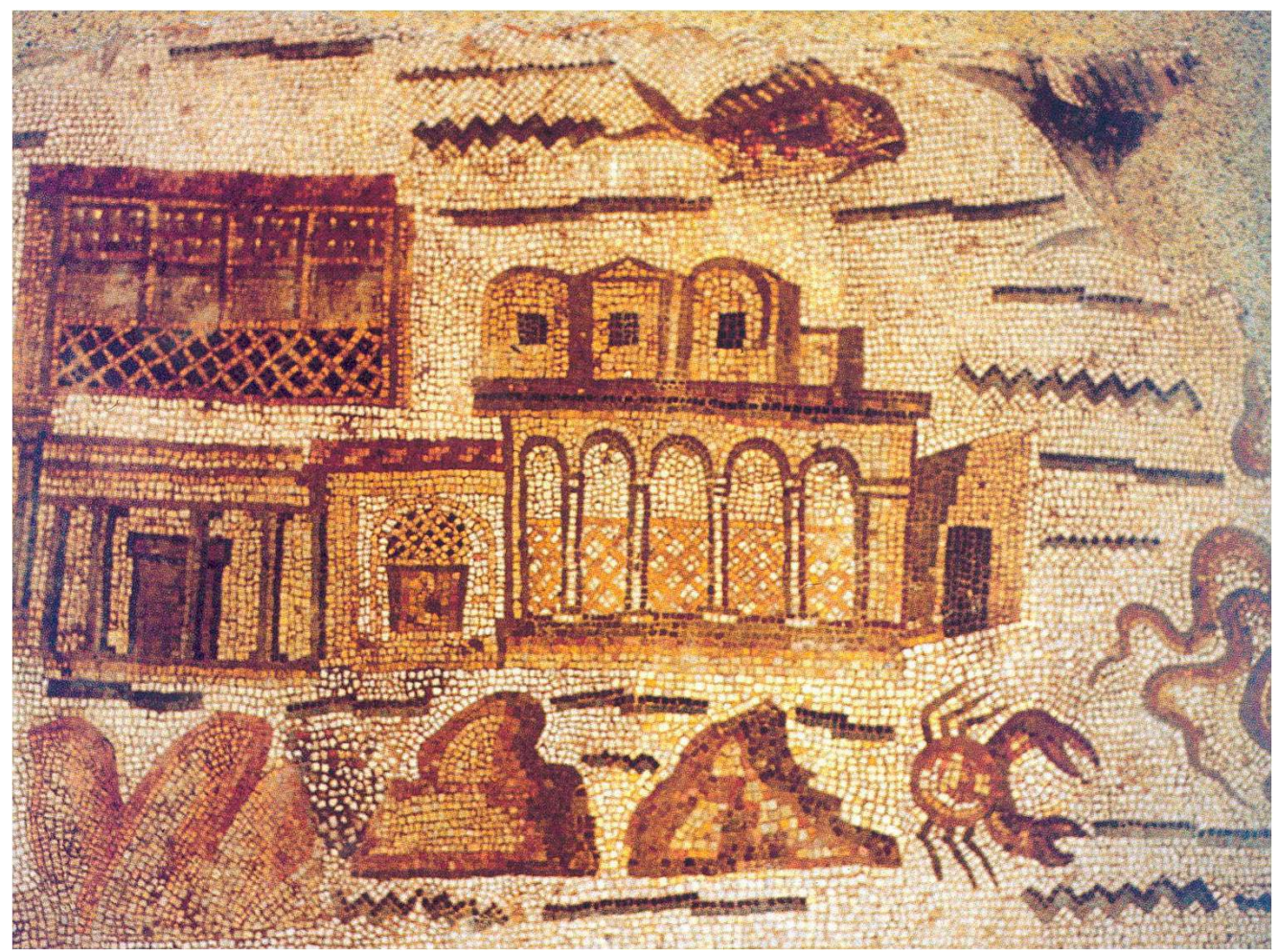

Figura 8: Detalle del mosaico de la Casa de Isguntus en Hippo Regius. Fuente: Ferdi, 1998.

Acerca de este aspecto, Boulinguez y Napoli (2008, 720-721) llaman la atención sobre los denominados clathri (en griego, kleithra) que aparecen en el nivel inferior del edificio representado, identificado como un enorme granero civil, dotado de un sistema de ventilación en los muros laterales y cámara de almacenaje sobreelevada. En este sentido, los clathri, también llamados cancelli, aludirían a dispositivos de protección, similares a una malla, que permitían evitar la intrusión en el sótano de animales y en particular de aves y roedores, con el pernicioso efecto en el grano, a través de pequeñas ventanas (modicis fenestellis) situadas en los muros laterales al nivel del suelo. Aun planteándose la altura excesiva de estos clathri (que no debieron ser de más de $80 \mathrm{~cm}$ para facilitar las operaciones de carga y descarga), los autores arguyen que quizás el mosaísta pudo haber exagerado lo que le parecía un aspecto digno de ser destacado en los graneros. Además, en la parte superior del muro del citado edificio, identifican un revestimiento de piedra almohadillada, a modo de refuerzo, según era frecuente en los muros de graneros situados junto a la costa, como en el de Leptis Magna (Tripolitania). Respecto a estos cierres situados en la zona de ventilación de los horrea, por el momento no se han documentado a nivel arqueológico; a lo sumo, se han localizado pequeños maineles en las aberturas de ventilación que permitían colocar rejillas de metal o madera, como se ha supuesto en el caso de los horrea militares de Gellygaer, Balmuildy o Corstopitum en Britannia (Gentry, 1976, 11).

Asimismo el edificio situado en primer plano y más próximo al puerto es igualmente identificado como un enorme granero civil, que, con una galería columnada también como el de Leptis Magna, podría haber sido destinado a las mercancías almacenadas para la annona, según se desprende también de la presencia de cancelli, esta vez interpretados como cierres o barandas, incluidos expresamente para resaltar que aquel espacio estaba convenientemente vigilado y custodiado (Boulinguez y Napoli, 2008, 723-724). A ello habría que añadir la característica forma de coronamiento del edificio, con dos cellae cubiertas por bóvedas de cañón y, en medio, una nave rectangular cubierta por una techumbre a dos aguas ligeramente inclinada.

Profundizando en la hipótesis de Marec (1958, 101-108) sobre la consideración de la representación musiva como una vista real de Hippo Regius, los dos graneros consignados, no necesariamente contemporáneos (Boulinguez y Napoli, 2008, 727-728), serían en el primer caso un edificio polivalente, con una planta baja con un gran depósito para almacenar aceite y vino y en el primer piso cellae para el almacenamiento de cereales (trigo, cebada, mijo, legumbres), mientras el segundo podría ser un edificio destinado por completo a los cereales y demostraría la necesidad de aumentar la capacidad de almacenamiento de la ciudad, quizás por la transformación de la ciudad en el denominado puerto dedicado a la annona.

Ante la representación tan esquemática y restos arqueológicos que confirmen dicha separación de productos en el interior de los horrea, en nuestra opinión resulta difícil aseverar esta hipótesis por el momento. No obstante, estamos de acuerdo con la hipótesis planteada de que el célebre mosaico de Hipona pretendía 


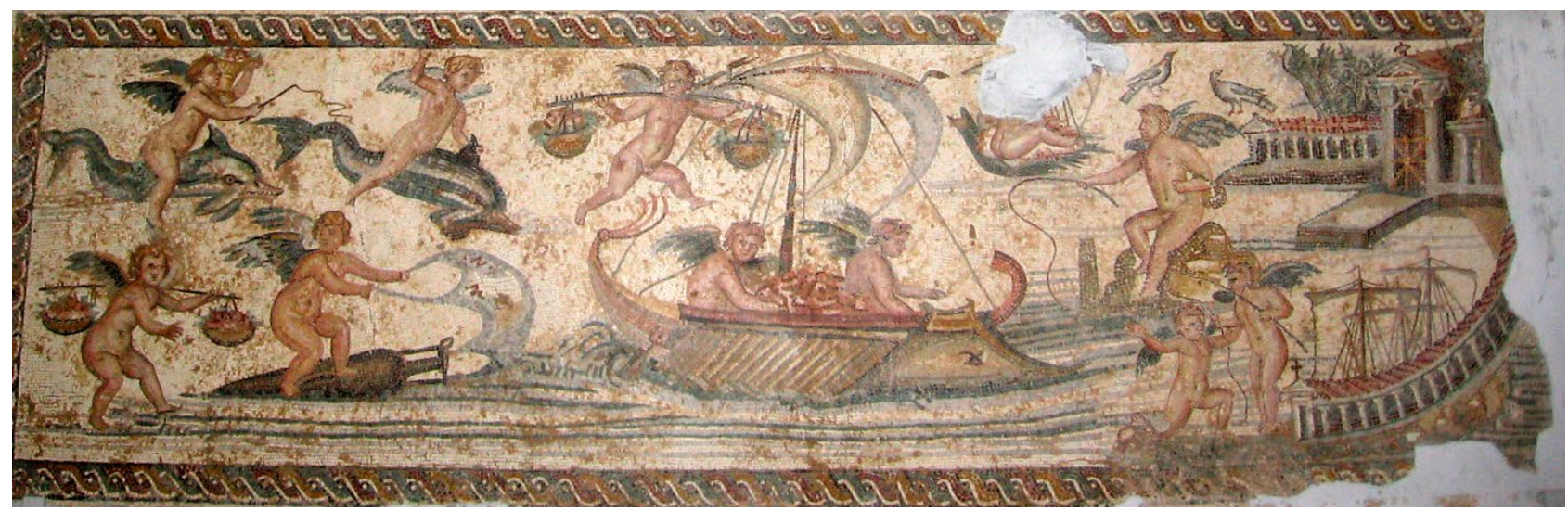

Figura 9: Mosaico de la denominada «villa del Nilo», próxima a Leptis Magna. Imagen: Luz Neira.

reflejar todas las riquezas del territorio, extendiéndose ante nuestros ojos no sólo sus recursos pesqueros, sino también aquellos otros de agua dulce y, sobre todo, sus abundantes recursos agrícolas.

Las excavaciones arqueológicas realizadas en determinados yacimientos nos permiten asociar dichas representaciones con los restos conservados de almacenes u horrea, como en el conocido puerto de Roma, aunque en este caso, se trata de monedas que enaltecen la construcción de las instalaciones en época de Claudio (64 d.C.) en el que destacan los almacenes (Keay y Millett, 2005, 305, fig. 9.3), de los que hasta el momento solamente unos escasos restos constructivos pueden ser interpretados como tales (Keay y Millett, 2005, 300) y de época de Trajano (103-111 d.C.) que muestra la presencia de horrea en torno al puerto hexagonal de los que se conocen más datos a nivel arqueológico que de los precedentes (Keay y Millett, 2005, 309, fig. 9.4).

Más interesante si cabe es el mosaico de la denominada «villa del Nilo» próxima a Leptis Magna en el que se representa un puerto dotado de un pórtico de columnas dóricas con una techumbre a doble vertiente (Aurigemma, 1960, 48, láms. 87-90) (Fig. 9). En la escena aparecen representados la alegoría del Nilo y una figuración de clara inspiración en el arte alejandrino (Aurigemma, 1960, 48-49, láminas 83-97), con instalaciones representadas con un carácter ideal (Noguera, 1995-1996, 229). Resulta difícil saber si el artesano se inspiró en modelos de puertos como el que existía en la propia ciudad norteafricana de Leptis Magna que cuenta con horrea que responden a este mismo tipo, con grandes arcadas abiertas hacia el mar (Bartoccini, 1958). Se ha podido testimoniar arqueológicamente horrea similares también en el puerto de la ciudad de Londinium (Londres) (Bateman y Milne, 1983; Milne, 1985) y en el vicus de Nauportus, situado en el extremo noreste del territorio de la colonia de Aquileia (Horvat, 2008). Asociar horrea concretos con escenas de mosaicos o figuraciones de otro arte es harto difícil si tenemos en cuenta que en diversos soportes se representan modelos de puertos con horrea de grandes arcadas, como en lucernas o relieves (Noguera, 1995-1996, 231).

\subsection{LOS ALMACENES RURALES}

Respecto a los horrea rurales, aunque poseemos mucha información sobre los mismos a nivel arqueológico (Salido, 2003-2004; 2008; 2011b), apenas contamos con datos relativos al alzado y aspecto exterior. Tampoco la figuración en mosaicos de villae y otros establecimientos rurales nos ofrecen información importante al respecto. Podríamos citar numerosas representaciones de escenas rurales con edificios rústicos que pudieron servir de graneros ${ }^{9}$, pero no existen datos que nos permitan confirmar su funcionalidad.

Cuando se muestran las fachadas de las villae, a nivel general pretenden mostrar la riqueza y aspecto monumental de las mismas, con torres defensivas que flanquean la entrada principal $^{10}$, y tampoco se representaron horrea en escenas agrícolas y relacionadas con la vida y los trabajos rústicos (como la cosecha y recogida de la mies), a diferencia de otras estructuras correspondientes a la pars rustica y fructuaria de las villae, como los torcularia (Balmelle y Brun, 2005) o los gallineros (Bertacchi, 1983). Resulta difícil determinar la función de algunas construcciones, aunque estén asociadas a tareas agrícolas como el labrado del campo, como se muestra en el mosaico de la domus de los Laberii en Uthina conservado en el Museo del Bardo (Fig. 10) o del pavimento musivo de El Alia (Fantar et alii, 1994, 98 y 133) (Fig. 11). Por otro lado, algunos edificios que pudieron corresponder a almacenes o graneros resultan difíciles de identificar. Es el caso de las construcciones representadas en el mosaico véneto de Oderzo donde se muestran edificios rústicos que Bertacchi (1983, 69,

9. Es el caso del mosaico de El Alia (Dunbabin, 1978, lámina III), Zliten (op. cit. Lámina XXXVI, 95 y 96) o Sidi Abdallah (op. cit. Lámina L, 125),

10. Para el estudio iconográfico véase Dunbabin, 1978, 50, 5659 y 119-122, láminas 11-13, 23, 34, 35, 40 y 109; Sarnowski, 1978; Blázquez, 1994, láminas I-XVI. Representaciones hispanorromanas en Arróniz, Centcelles y Toledo (Blázquez y Mezquíriz, 1985, 21). 


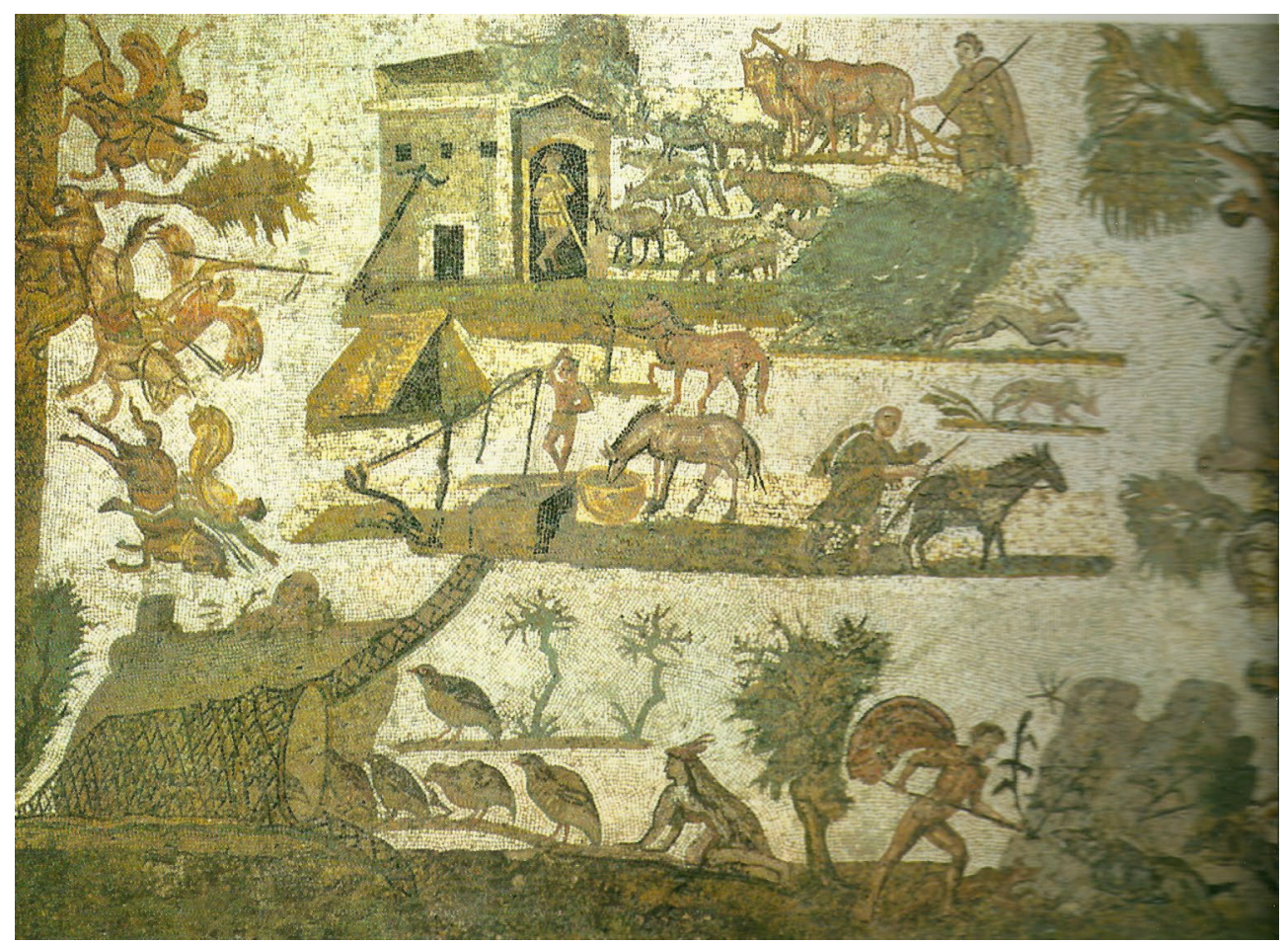

Figura 10: Mosaico de la domus de los Laberii conservado en el Museo del Bardo. Fuente: Fantar et alii, 1994, 98.

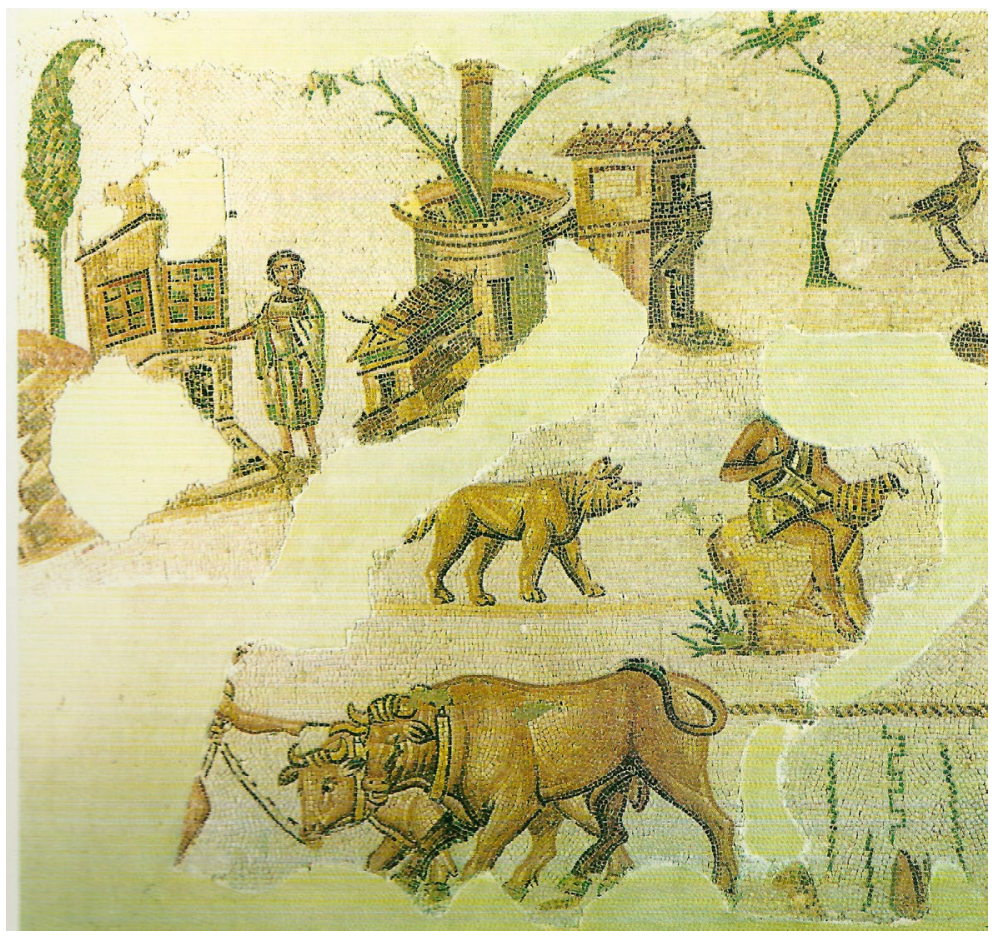

Figura 11: Pavimento musivo de El Alia. Fuente: Fantar et alii, 1994, 133.

lámina CCXXXI. 1) interpreta como posibles horrea, faenilia o palearia, pero que no responde al típico granero sobreelevado aislado que conocemos por los testimonios arqueológicos (Fig. 12). Es posible que cumplieran funciones de almacenaje, aunque a tenor de la imagen parcial conservada, nos resulta difícil aseverar que los estantes horizontales representados en la imagen corresponden a tabulata o pavimentos sobreelevados, lo que nos confirmaría el uso de los mismos como granaria u horrea ${ }^{11}$. Recientemente, se ha propuesto la identificación de algunos edificios

11. Sobre esta cuestión, véase Salido, 2011, 63-67. 


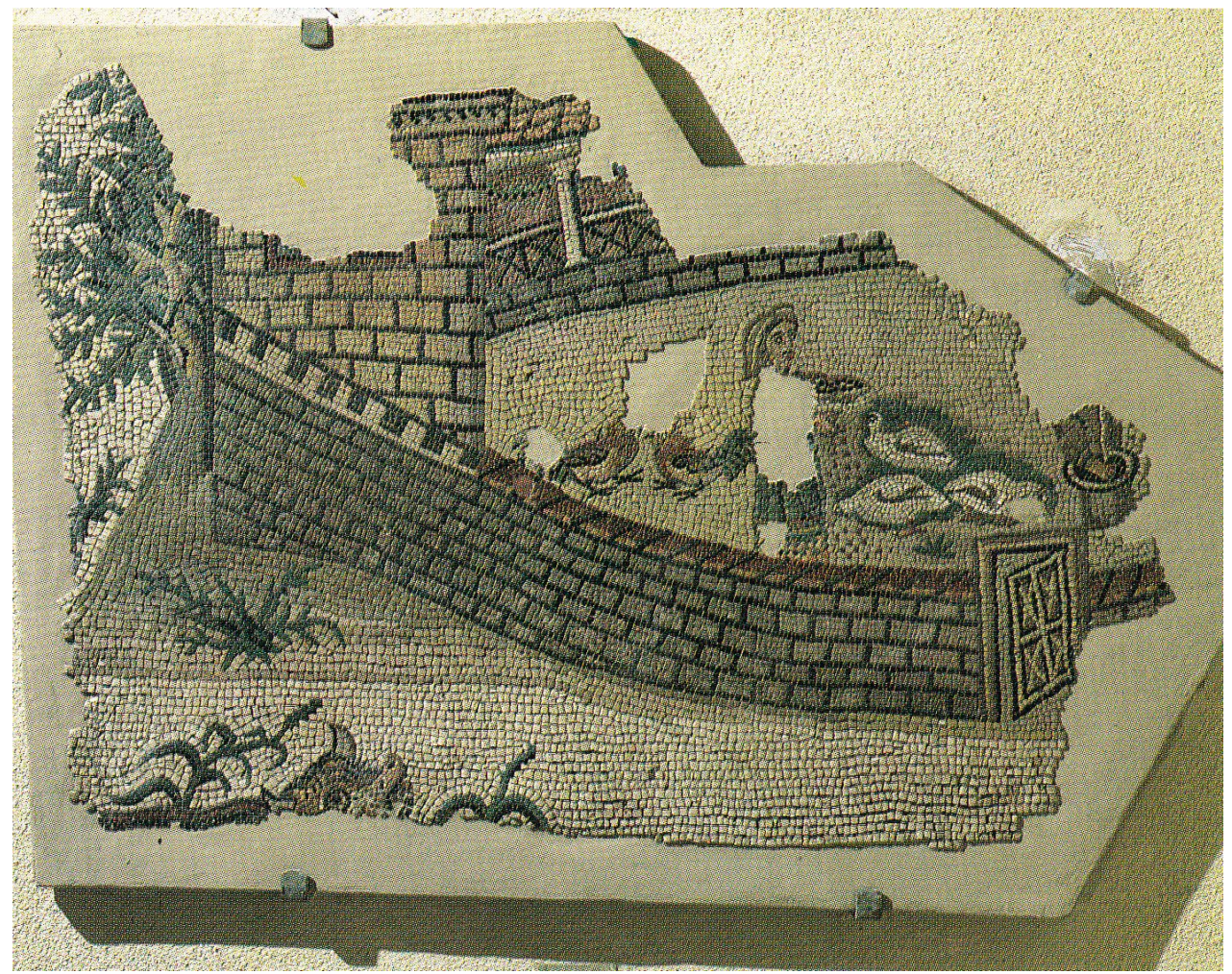

Figura 12: Mosaico de Oderzo. Imagen: Bertacchi, 1983, lámina CCXXXI, 1.

representados en segundo plano como horrea rurales. Es el caso del mosaico proconsular del trifolium de Thabraca (Museo del Bardo), donde, según la propuesta de Boulinguez y Napoli $(2008,723)$, el edificio representado corresponde a un granero con entrada situada a bastante altura. A tenor de los detalles de la propia representación, esta hipótesis nos resulta difícil de mantener.

\section{REFLEXIONES FINALES. APORTACIONES DE LA MUSIVARIA ROMANA AL ESTUDIO DE LOS HORREA ROMANOS}

La identificación de los horrea o almacenes en las figuraciones y escenas realizadas en mosaico resulta difícil debido a varios motivos, tales como su similitud con otros edificios que responden a modelos constructivos parecidos (macella, valetudinaria, etc.), el papel secundario que cumplen dentro de las escenas representadas, la dificultad para asociar edificios con actividades estrechamente relacionadas con la producción, almacenaje, venta o redistribución del grano y otros productos conservados; por otro lado, la utilización de cartones por parte de los artesanos romanos nos impide reconocer estas estructuras en paisajes, puertos, construcciones o restos arquitectónicos concretos.

A pesar de estos problemas, podemos reconocer algunas construcciones que pueden corresponder a almacenes que forman parte de escenas urbanas y portuarias. A nivel general, los horrea representados responden a dos tipos de construcciones: almacenes con cellae organizadas en torno a un patio central y edificios con grandes arcadas abiertas al mar. El primer tipo, bien representado en el mosaico de la villa romana de Bad Kreuznach, ha sido perfectamente constatado a nivel arqueológico en diferentes regiones del Mediterráneo Occidental. La escena nos permite analizar construcciones anexas a los almacenes, como el supuesto sacellum representado en el mosaico citado, que bajo nuestro punto de vista podría realmente corresponder a una torre de vigilancia, en estrecha relación con la importancia de los productos conservados en este tipo de edificaciones.

El segundo tipo de almacén, con grandes cellae orientadas hacia el mar, aparece representado en mosaicos como el de la Casa de Isguntus en Hippo Regius y en el de la villa del Nilo próxima a Leptis Magna. A nivel arqueológico, se ha podido constatar en las grandes instalaciones del Portus de Roma y en algunas estructuras portuarias como Londinium y Nauportus. Las representaciones nos muestran el alzado de las estancias o cellae, dimensiones que desconocemos a nivel arqueológico dado el estado de arrasamiento de los muros, y de igual modo nos informan de la existencia de detalles constructivos como los cancelli, que por el momento no se han reconocido a nivel arqueológico, ni como elementos de protección de los horrea ni en el sistema de ventilación de los graneros, de ahí la dificultad para interpretar la representación del mosaico de Hippo Regius. 
Por último, hemos tratado de señalar las dificultades para identificar los horrea rurales en las numerosas escenas rústicas, muy frecuentes en regiones como el norte de África. Aunque algunas construcciones han sido interpretadas como almacenes, los argumentos esgrimidos nos resultan poco convincentes. Así que, respecto a estas estructuras rústicas, por el momento tenemos que atenernos más a la información que nos proporcionan las fuentes arqueológicas que a la imagen ofrecida por el arte musivario.

Dr. Javier Salido Domínguez
Escuela Española de Historia y Arque
Via di Torre Argentina, 18
00186 Roma (Italia).
pjaviers@hotmail.com
Dra. Luz Neira Jiménez
Universidad Carlos III de Madrid
C/Madrid, 128
28903 Getafe (Madrid)
lneira@hum.uc3m.es

\section{BIBLIOGRAFÍA}

ALZON, C., 1964: Problèmes relatifs à la location des entrepôts en droit romain, París.

ASTOLFI, F., GUIDOBALDI, F y PRONTI, A., 1978: «Horrea Agrippiana», Archeologia Classica, 30, 31-107.

AUPERT, P. y DASSIÉ, J., 1997-1998: «L'urbanisme d'une agglomération secondaire: nouvelles découvertes aériennes à Barzan», Aquitania, 15, 167-186.

AUPERT, P., FINCKER, M. y TASSAUX, F., 1998: «Agglomérations secondaires de 1'Aquitaine atlantique», en $\mathrm{P}$. GROS (Dir.), Villes et Campagnes en Gaule romaine, Comité des travaux historiques et scientifiques. $120^{\circ}$ Congrès national des Sociétés historiques et scientifiques (Aix-en-Provence, 1995), 45-69, París.

AURIGEMMA, S., 1960: L'Italia in Africa. I Mosaici, Roma.

BACKER, P., 2002: «The Roman Military Valetudinaria: Fact or Fiction», en R. ARNOTT (Ed.), The Archaeology of Medicine, Proceedings of the Theoretical Archaeology Group 1998, 69-80, Oxford.

BALIL, A., 1984: «Monumentos alejandrinos y paisajes egipcios en un mosaico romano de Toledo (España)», Studi in onore di Achille Adriani, vol. 3, 433-439, Roma.

BALMELLE, C. y BRUN, J.-P., 2005: «La vigne et le vin dans la mosaique romaine et byzantine», en $\mathrm{H}$. MORLIER (Ed.), La mosaique greco-romaine IX, 899-921, Roma.

BARBET, A., 1999: «Une peinture de bassin dans la maison des nymphes à Nabeul. Ses relations avec les mosaïques», en M. ENNAÏFER y A. REBOURG (Eds.), La mosaïque greco-romaine VII, volumen I, 311-319, Túnez.

BARRAUD, D. y MAURIN, L., 1996: «Bordeaux au BasEmpire. De la ville païenne à la ville chrétienne (IIIeVIe siècles)», Aquitania, 14, 35-53.
BARTOCCINI, R., 1958: Il porto romano di Leptis Magna, Bollettino del Centro studi per la storia dell'architettura 13, Roma.

BATEMAN, N. y MILNE, G., 1983: «A Roman Harbour in London. Excavations and Observations near Pudding Lane, City of London 1979-82», Britannia, 14, 207-226.

BEDON, R., 2001: Atlas des villes, bourgs, villages de France au passé romain, 137-140, Paris.

BEJARANO OSORIO, A. M., 2002: «Una ampulla de vidrio decorada con la planta topográfica de la ciudad de Puteoli», Mérida, excavaciones arqueológicas, 8, 513-532.

BERTACCHI, L., 1982: «Edilizia civile nel IV secolo ad Aquileia», Antichità Altoadriatiche, 22 (2), 337-357.

BERTACCHI, L., 1983: «Ricomposizione del mosaico opitergino con villa rustica», Mosaïque: recueil d'hommages à Henri Stern, 65-74, París.

BIRLEY, E., 1959: «Excavations at Corstopitum, 19061958», AA, 4 (37), 1-31.

BLÁZQUEZ, J.M., 1982: Mosaicos romanos de la Real Academia de la Historia. Ciudad Real, Toledo, Madrid y Cuenca, CME V, Madrid.

BLÁZQUEZ, J. M., 1994: «El entorno de las villas en los mosaicos de África e Hispania», L'Africa Romana X, 1.171-1.187, Sassari.

BLÁZQUEZ, J. M. y MEZQUÍRIZ, M. A., con la colaboración de M. L. Neira y M. Nieto, 1985, Mosaicos romanos de Navarra, Madrid.

BOULINGUEZ, C. y NAPOLI, J., 2008: «Hippone, port de l'annone: la contribution de l'iconographie», Africa romana XVII, 703-730, Roma.

DELLONG, E. (dir.), 2002: CAG 11/1. Narbonne et le Narbonnais, París.

DORÉ, J. N., 2008: Corbridge. Roman Site, Londres.

DUNBABIN, K. M. D., 1978: The Mosaics of Roman North Africa, Oxford.

EIDEN, H. y MYLIUS, H., 1949: «Untersuchungen an den spätrömischen Horrea von St. Irminen in Trier», Trierer Zeitschrift, 18, 73-98.

FANTAR, M. H. ET ALII, 1994: La mosaïque en Tunisie, París.

FERDI, S., 1998: Mosaïque des eaux en Algérie. Un langage mythologique des pierres, Argel.

FRÉZOULS, E., (Dir.), 1997: Les villes antiques de la France. III, 1. Lyonnaise. Autun, Chartres, Nevers, Etudes d'archéologie et d'histoire ancienne, Paris.

GASPARRI, C., 1983-1984: «Due mosaici antichi in S. Maria in Trastevere», en N. BONACASA y A. DI VITA (Eds.), Alessandria e il mondo ellenistico-romano: studi in onore di Achille Adriani, 672-676, Roma.

GENTRY, A. P., 1976: Roman military stone-built granaries in Britain, BAR International Series 32, Oxford.

GIANFROTTA, P. A., 2012: «Da Baia agli horrea del Lucrino: aggiornamenti», Archeologia Classica, LXII, 277-344.

GISSINGER, B., 2002: Recherches sur le site fortifié de Strasbourg durant l'antiquité tardive: le castrum d'Argentoratum, BAR international series 1024, Oxford. 
HORVAT J., 2008: «Early Roman horrea at Nauportus», Mélanges de l'Ecole française de Rome. Antiquité, 120 (1), 111-121.

KEAY, S. y MILLETT, M., 2005: «Portus in context», en S. KEAY, M. MILLETT, L. PAROLI y K. STRUTT (Eds.), Portus: an archaeological survey of the port of imperial Rome, 297-306, Londres.

KEAY, S., MILLETT, M. y STRUTT, K., 2005b: «The Survey Results», S. Keay, M. Millett, L. Paroli y K. Strutt, Portus: an archaeological survey of the port of imperial Rome, Archaeological monographs of the British School at Rome 15, 71-172, Londres.

LA GLAY, M. D. y TOURRENC, S., 1970: Saint-Romainen-Gal. Quartier urbain de Vienne gallo-romaine, Lyon.

LAVAGNE, H., 2005: «Une mosaïque romaine imitant une peinture sacro-idyllique», en H. MORLIER (Ed.), La mosaïque gréco-romaine IX, volumen I, 559-566, Roma.

LING, R., 1991: Roman Paintings, Cambridge.

LÓPEZ MONTEAGUDO, G., 1994: «Representaciones de ciudades en mosaicos romanos del Norte de África», L'Africa romana X, 1242-1243.

LUSCHIN, E. M., 2002: Cryptoporticus: zur Entwicklungsgeschichte eines multifunktionalen Baukörpers, Ergänzungshefte zu den Jahresheften des Österreichischen Archäologischen Institutes 5, Wien.

MANNING, W. H., 1975: «Roman military timber granaries in Britain», $S J, 32,105-129$.

MAREC, E., 1958, «Trois mosaïques d'Hippone à sujets marins», Libyca, 6, 99-122.

MILNE, G., 1985: The port of Roman London, Londres.

MINAUD, G., 2004: «Regard sur la comptabilité antique romaine. La mosaïque de l'aula des mensores à Ostie, des doigts et des comptes», MEFRA, 116 (1), 437-468.

MIRABELLA ROBERTI, M., 1984: Milano romana, Milán.

NEIRA JIMÉNEZ, M. L., 1997: «Sobre la representación de ciudades marítimas en mosaicos romanos», Espacio. Tiempo y Forma. Serie II. Historia Antigua, 10, 219-251.

NOGUERA CELDRÁN, J. M., 1995-1996: «Instalaciones portuarias romanas: representaciones iconográficas y testimonio histórico», Anales de prehistoria y arqueología, 11-12, 219-235.

ORDÓÑEZ AGULLA, S. y GONZÁLEZ ACUÑA, D., 2011: «Horrea y almacenes en Hispalis: evidencias arqueológicas y evolución de la actividad portuaria», en J. ARCE y B. GOFFAUX (Eds.), Horrea d'Hispanie et de la Méditerranée romaine, 159-184, Madrid.

PAPI, E. y MARTORELLA, F., 2007: «Il grano della Tingitana», en E. PAPI (Ed.), Supplying Rome and the Empire (Siena-Certosa, 2004), Journal of Roman Aarchaeology Supplementary Series 69, 85-96, Portsmouth.

PAPI, E. y MARTORELLA, F., 2009: «I granai della $\mathrm{Nu}$ midia», L'Afrique du Nord de la protohistoire à la conquête arabe, Antiquités Africaines, 43, 171-186

RABOLD, B., 1995: «Das Bad Kreuznacher Oceanusmosaik. Neue Aspekte zu Handel und Verkehr im Mainzer Grossraum», Archäologisches Korrespondenzblatt, 25, 221-232.

RICKMAN, G., 1971: Roman granaries and store buildings, Cambridge.
RUFFIER, O. y DUPONT, P., 1993: «L'operation archéologique de la rue Barbès à Bourges: 1'occupation antique de la rive gauche de 1'Auron», Cahiers d'archéologie et d'histoire du Berry, 116, 35-46.

SALIDO, J., 2003-2004: «La documentación literaria aplicada al registro arqueológico: las técnicas de construcción de los graneros romanos rurales», Espacio, Tiempo y Forma. Serie I: Prehistoria y Arqueología, 16-17, 463-478.

SALIDO, J., 2008: «Los sistemas de almacenamiento y conservación de grano en las villae hispanorromanas», en C. FERNÁNDEZ OCHOA, V. GARCÍA-ENTERO y F. GIL SENDINO (Eds.), Las villae tardorromanas en el Occidente del Imperio. Arquitectura y función, IV Coloquio Internacional de Arqueología de Gijón (26, 27 y 28 de Octubre de 2006), 693-706, Gijón.

SALIDO, J., 2010: Horrea, granaria et siri. Estructuras de almacenamiento de grano en el Occidente del Imperio Romano, Tesis doctoral, Universidad Autónoma de Madrid.

SALIDO, J., 2011: Horrea Militaria. El aprovisionamiento del cereal al ejército en el Occidente del Imperio Romano, Anejos de Gladius 14, Madrid.

SALIDO, J., 2011b: «El almacenamiento de cereal en los establecimientos rurales hispanorrromanos», en $\mathrm{J}$. ARCE y B. GOFFAUX (Eds), Horrea d'Hispanie et de la Méditerranée romaine, 127-142, Madrid.

SALIDO, J., 2012: «Manifestaciones religiosas y espacios sacros en los Horrea del Occidente del Imperio Romano», Madrider Mitteilungen, 53, 310-341.

SALIDO, J., 2013: «El abastecimiento de grano a las ciudades hispanorromanas. Producción, almacenaje y gestión», Archivo Español de Arqueología, 86, 131-148.

SALIDO, J. y MORAIS, R., 2014: «El horreum de la ciudad romana de Bracara Augusta (Braga, Portugal): funcionalidad, tipología y contexto», Sautuola, en prensa.

SARNOWSKI, T., 1978: Les représentations de villas sur les mosaïques africaines, Varsovia.

SEBASTIANI, R. y SERLORENZI, M., 2011: «Nuove scoperte dall'area di Testaccio (Roma): tecniche costruttive, riuso e smaltimento dei contenitori anforici pertinenti ad horrea e strutture utilitarie di età imperiale», en J. ARCE y B. GOFFAUX (Eds), Horrea d'Hispanie et de la Méditerranée romaine, 67-96, Madrid.

VIRLOUVET, C., 1995: Tessera frumentaria: les procédures de distribution du blé public à Rome à la fin de la République et au début de l'Empire, Bibliothèque des écoles françaises d'Athènes et de Rome 286, Roma.

VISCONTI, C. L., 1884: Les monuments de sculpture antique du musée Torlonia, Roma.

ZAHARIADE, M., 2007: «Autricum», en M. ZAHARIADE (Ed.), Lexicon of the Greek and Roman Cities and Place Names in Antiquity Ca. 1500 B.C.-Ca. A.D. 500, Fascicule 8, 1235-1237, Amsterdam.

Recepción: 18-02-2014

Aceptación: 07-04-2014 